\title{
DM4-Conjugated Anti-Cripto Monoclonal Antibody BIIB015
}

National Cancer Institute

\section{Source}

National Cancer Institute. DM4-Conjugated Anti-Cripto Monoclonal Antibody B/IB015.

NCI Thesaurus. Code C77864.

A humanized IgG1 monoclonal antibody directed against the cell surface-associated protein Cripto and conjug ated to the maytansinoid DM4 with potential antineoplastic activity. The monoclonal antibody moiety of DM4-conjug ated anti-Cripto monoclonal antibody BIIB015 binds to the tumor associated antigen (TAA) Cripto; upon internalization, the DM4 moiety binds to tubulin and disrupts microtubule assembly/disassembly dynamics, resulting in inhibition of cell division and cell growth of Cripto-expressing tumor cells. Constitutively expressed during embryogenesis, Cripto belongs to the EGF-CFC family of growth factor-like molecules and plays a key role in signaling pathways of certain transforming growth factor-beta superfamily members; as a TAA, Cripto is overexpressed in carcinomas such as those of the breast, ovary, stomach, lung, and pancreas while its expression is absent in normal tissues. 